\title{
Hydrophilic 1,10-phenanthroline derivatives for selective Am(III) stripping into aqueous solutions
}

Stefano Scaravaggi ${ }^{\mathrm{a}}$, Elena Macerata ${ }^{\mathrm{a},{ }^{*}}$, Michele Galletta $^{\mathrm{a}}$, Eros Mossini $^{\mathrm{a}}$, Alessandro Casnati $^{\mathrm{b}}$, Mattia Anselmi $^{\mathrm{b}}$, Francesco Sansone ${ }^{\mathrm{b}}$, Mario Mariani ${ }^{\mathrm{a}}$

a Department of Energy, Politecnico di Milano, Piazza L. da Vinci 32, 20133 Milano, Italy; Fax: +39.02.23996309; Tel: +39.02.23996385;

${ }^{b}$ Department of Chemistry, University of Parma, Parco Area delle Scienze 17/a, 43124 Parma, Italy; Fax: +39.0521.905472; Tel:+39.0521.905458;

*Corresponding author e-mail: elena.macerata@polimi.it

\begin{abstract}
The novel and fully combustible hydrophilic 1,10-phenantroline-2,9-dicarboxamide (1) was synthesized and investigated as Am(III) stripping agent in a simulated advanced hydrometallurgical process, in comparison with two other 1,10-phenanthroline-based ligands 2 and 3. The stripping efficiency and the Am(III)/lanthanides(III) selectivity of the TODGA (org) / phen-derivative (aq) extracting system were studied under several experimental conditions by liquid-liquid extraction tests. The results obtained clarify the main limitations of these ligands in the scope of the hydrometallurgical reprocessing but also enable to get indications to steer future investigations in the domain of the selective An(III) recovery for the advanced reprocessing of Spent Nuclear Fuel by hydrophilic ligands.
\end{abstract}

\section{Keywords}

1,10-phenanthroline, hydrophilic ligands, solvent extraction, An/Ln separation, selective Am stripping, $i$-SANEX

\section{INTRODUCTION}

The very long half-lives of some radionuclides present in Spent Nuclear Fuel (SNF) entail that a part of this waste will remain potentially hazardous for hundreds of thousands of years, thus making the development of nuclear power plants less attractive and the extensive use of nuclear energy less sustainable for future generations. SNF reprocessing, based on the Partitioning and Trasmutation (P\&T) of the long-lived radionuclides (in particular Minor Actinides, MAs) into shorter-lived or stable elements [1-3], has been proposed as a feasible process to reduce the radiotoxicity of waste, to optimize the use of natural resources and to increase the resistance to nuclear proliferation, thus making nuclear power more sustainable in the future [4]. The treatment of recovered MAs in suitable nuclear reactors is inhibited if neutron poisons, such as lanthanides and other fission and corrosion products, are present in the fuel. Therefore, the challenging task of selective Actinide (An) recovery from the PUREX raffinate has been the main object of a series of European collaborative Projects of the Euratom Research Programme (i.e. NEWPART [5], PARTNEW [6], EUROPART [7,8] and ACSEPT [9]): among the several hydrometallurgical processes developed for the An/Ln separation [10], the $i$-SANEX (innovative Selective ActiNide EXtraction, a heterogeneous recycling of An) process and the GANEX (Group ActiNide EXtraction, a homogeneous recycling) process deserve mention [11, 12]. In the $i$-SANEX concept An(III) has to be selectively separated from $\mathrm{Ln}(\mathrm{III})$ after all these trivalent metal ions are simultaneously removed from the dissolved nuclear waste resulting from the uranium and plutonium recovery of PUREX; the GANEX process, on the contrary, comprises a first cycle for the U recovery, in place of the corresponding PUREX step, and a second two-steps cycle for the An selective stripping [13-15]. Within the studies dedicated to these technological issues, the major difference between $\mathrm{An}(\mathrm{III})$ and $\mathrm{Ln}(\mathrm{III})$ ions lies in the greater covalent character in the M-L $(\mathrm{L}=\mathrm{soft}$ 
donor ligands) bonding of the An(III) ions [16-21]. Thus, several families of ligands having at least a heterocyclic nitrogen atom were tested [18-21], in particular, the terdentate 2,6-bis-(1,2,4-triazin-3-yl)pyridine (BTPs, I) [22], the quadridentate 6,6'-bis(1,2,4-triazin3-yl)bipyridine (BTBPs, II) [23-25] and the 2,9-bis-(1,2,4-triazin-3-yl)-1,10-phenanthroline (BTPhen, III) [26] (see Figure 1).
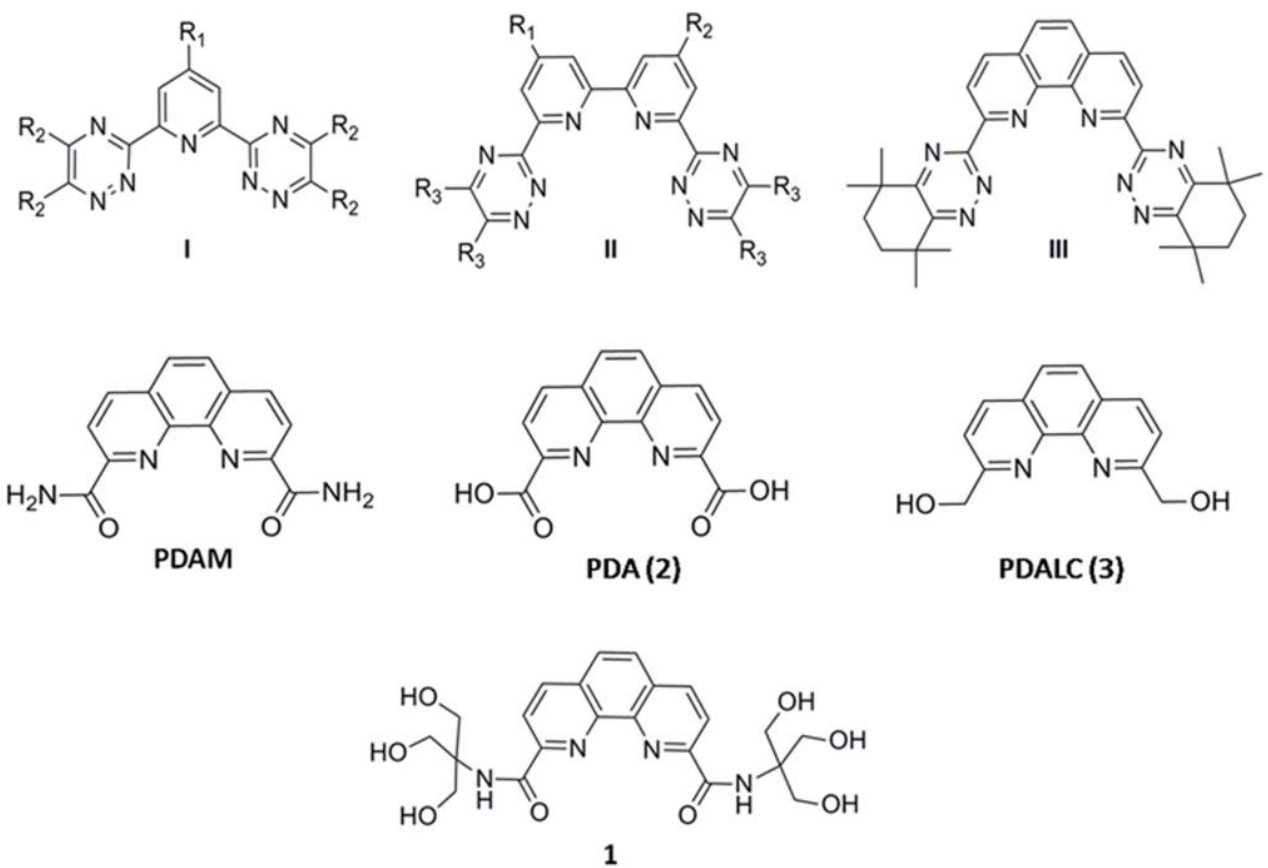

Figure 1 Molecular structures of BTP-(I), BTBP-(II), BTPhen (III) and PDAM ligands, together with the hydrophilic 1,10phenantroline derivatives PDA (2), PDALC (3) and 1 used in this study.

The newly proposed ligands should possibly satisfy the environmental-friendly CHON principle, which means that the selected molecules must contain only carbon, hydrogen, oxygen and nitrogen atoms enabling, after their life-cycle, a complete incineration. The metal ion complexing properties of phenanthroline-based ligands is an extremely active field in coordination chemistry, thanks also to the simple synthesis [27-33]. In particular, the complexation properties of PDA (1,10-phenanthroline-2,9-dicarboxylic acid, 2) [34, 35], PDALC (2,9-bis(hydroxymethyl)-1,10-phenanthroline, 3) [36-38] and PDAM (1,10-phenanthroline-2,9-dicarboxamide) [39] (see Figure 1) towards transition metal, $\mathrm{Ln}(\mathrm{III})$ and $\mathrm{Th}^{4+}$ or $\mathrm{UO}_{2}{ }^{2+}$ ions have been already studied [40, 41] but, to our knowledge, these ligands were not tested towards An(III) complexation or the An/Ln separation. However, the high level of preorganization of such kind of extractants and the metal ion size-based recognition dependent on a fairly rigid cleft (not on the presence of a cavity as in macrocycles) make them very attractive for such application [42, 43].

Thanks to the knowledge acquired within the field of the SNF hydrometallurgical reprocessing [44-47], we are herein reporting, for the first time, the synthesis and application of the hydrophilic complexant 1,10-phenanthroline-2,9-dicarboxamide, $N^{2}, N^{9}$-bis[1,3dihydroxy-2-(hydroxymethyl)propan-2-yl] (1) (see Figure 1) as Am(III) selective stripping agent in the $i$-SANEX process. Similarly, the simpler hydrophilic phenanthroline-based ligands PDA (2) and PDALC (3), presenting the same donor set but with different coordinating ability, were tested and compared to $\mathbf{1}$.

\section{EXPERIMENTAL STUDIES}

\section{Experimental conditions}

\section{$\underline{\text { General methods and chemicals }}$}


All the moisture sensitive reactions were carried out under a nitrogen atmosphere. All dry solvents were prepared according to standard procedures and stored over molecular sieves. Melting points were determined on an Electrothermal apparatus in capillaries sealed under nitrogen. ${ }^{1} \mathrm{H}$ and ${ }^{13} \mathrm{C}$ NMR spectra were recorded on Bruker AV300 and AV400 spectrometers. J coupling constants are given in Hz. Partially deuterated solvents were used as internal standards. ESI-MS spectra were recorded on a Waters single quadrupole instrument SQ Detector, in positive mode, by dissolving the samples in methanol. TLC was performed on Merck 60 F254 silica gel and flash column chromatography on 230-400 mesh Merck 60 silica gel. Carbobenzyloxy-protected tris(hydroxymethyl)aminomethane (Cbz)-TRIS, 4) as well as the hydrophilic 1,10-phenanthroline derivatives 2 and 3 were prepared according to the synthetic procedures already known in literature [48-50].

All commercially available chemicals (Sigma-Aldrich) used in this study were analytical reagent grade and used without further purification. Nitric acid was $70 \%$ in concentration, ACS grade. Ammonium nitrate was $\geq 99.0 \%$ purity. $\mathrm{La}\left(\mathrm{NO}_{3}\right)_{3} \cdot 6 \mathrm{H}_{2} \mathrm{O}(99.99 \%)$, $\mathrm{Ce}\left(\mathrm{NO}_{3}\right)_{3} \cdot 6 \mathrm{H}_{2} \mathrm{O}(99.0 \%), \operatorname{Pr}\left(\mathrm{NO}_{3}\right)_{3} \cdot 6 \mathrm{H}_{2} \mathrm{O}(99.9 \%), \mathrm{Nd}\left(\mathrm{NO}_{3}\right)_{3} \cdot 6 \mathrm{H}_{2} \mathrm{O}(99.9 \%), \mathrm{Sm}\left(\mathrm{NO}_{3}\right)_{3} \cdot 6 \mathrm{H}_{2} \mathrm{O}(99.9 \%), \mathrm{Eu}\left(\mathrm{NO}_{3}\right)_{3} \cdot 5 \mathrm{H}_{2} \mathrm{O}(99.9 \%)$, $\mathrm{Gd}\left(\mathrm{NO}_{3}\right)_{3} \cdot 6 \mathrm{H}_{2} \mathrm{O}(99.9 \%)$ and $\mathrm{Y}\left(\mathrm{NO}_{3}\right)_{3} \cdot 6 \mathrm{H}_{2} \mathrm{O}(99.8 \%)$ were used to prepare a simplified HAR (High Active Raffinate) simulating stock solution in $3 \mathrm{M} \mathrm{HNO}_{3}$. The radioactive certified reference materials, ${ }^{241} \mathrm{Am}\left(\mathrm{NO}_{3}\right)_{3}$ in $1 \mathrm{M} \mathrm{HNO}_{3}\left(\operatorname{carrier} 20 \mathrm{mg} \mathrm{L} \mathrm{H}^{-1} \mathrm{Sm}\left(\mathrm{NO}_{3}\right)_{3}\right)$ and of ${ }^{152} \mathrm{EuCl}_{3}$ in $1 \mathrm{M} \mathrm{HCl}$ (carrier $10 \mu \mathrm{g} \mathrm{g}^{-1} \mathrm{EuCl}_{3}$ ) solutions, were supplied by Eurostandard CZ (Czech Republic) and CERCA-LEA (France), respectively. N,N,N',N'-tetraoctyl diglycolamide (TODGA) was kindly provided by the Institute of Chemical Research of Catalonia (ICIQ), Spain. The organic solutions were prepared by dissolving weighted quantities of TODGA in a mixture of kerosene/1-octanol 95/5\% v/v.

\section{Solubility and Extraction experiments}

The solubility of $\mathbf{2}$ and $\mathbf{3}$ in water or nitric acid solutions is reported in literature [34, 36, 37, 39], while the solubility of $\mathbf{1}$ was evaluated by stepwise dissolution of a weighted amount of the ligand in water and/or in different nitric acid solutions at room temperature and in some cases at temperatures up to $50^{\circ} \mathrm{C}$. The diluent was added stepwise and the suspension was sonicated after each addition until a clear solution was obtained.

The liquid-liquid extraction tests were performed following a standard protocol. Nitric acid aqueous phases containing the cations to be extracted were contacted with an equal volume of organic phase in closed single-use Eppendorf microtubes at room temperature (T $=22 \pm 2{ }^{\circ} \mathrm{C}$ ). Once contacted, the organic and aqueous phases were vigorously shaken with a mixer for $1 \mathrm{~h}$. The mixing time of $1 \mathrm{~h}$ was found to be enough for the system to reach the equilibrium. After the phase separations by centrifugation, an aliquot of $200 \mu \mathrm{L}$ from each phase was subsampled and analysed. The radiotracers were quantified by $\gamma$-spectrometry (2”x2” NaI(T1), Silena SNIP 201 N MCA) exploiting the $\gamma$-lines at $59.5 \mathrm{keV}$ and $121.8 \mathrm{keV}$ for ${ }^{241} \mathrm{Am}$ and ${ }^{152} \mathrm{Eu}$, respectively. The concentrations of stable elements (Y and lanthanides) were determined by Inductively Coupled Plasma Mass Spectrometry (ThermoFisher X-Series ${ }^{\mathrm{II}}$ ICP-MS) as direct measurements on the aqueous phases after adequate dilution, and after mineralization by means of microwave oven for the organic phases. Distribution coefficients, $\mathrm{D}_{\mathrm{M}}$, were calculated as the ratio between the radioisotope activity or the element concentration in the organic and in the aqueous phases, whereas the selectivity for Ln over Am is expressed by the separation factor, $\mathrm{SF}_{\mathrm{Ln} / \mathrm{Am}}, \mathrm{defined}_{\mathrm{as}}$ the ratio of distribution coefficients $\mathrm{D}_{\mathrm{Ln}} / \mathrm{D}_{\mathrm{Am}}$. The activity balance was checked and the overall accuracy in the determination of $\mathrm{D}_{M}$ is within $3 \%$. In the series of solvent extraction tests named "Screening tests", the stripping agents were dissolved in nitric acid solutions spiked with ${ }^{241} \mathrm{Am}$ and ${ }^{152} \mathrm{Eu}$. This aqueous phase was contacted and mixed with an organic phase composed of TODGA in a mixture of kerosene/1-octanol 95/5\% v/v. In the series of experiments named "Stripping tests", the organic TODGA solution in kerosene/1octanol 95/5\% v/v was contacted with a $3 \mathrm{M}$ nitric acid solution spiked with ${ }^{241} \mathrm{Am}$ and ${ }^{152} \mathrm{Eu}$ or a $3 \mathrm{M}$ nitric acid solution containing ${ }^{241} \mathrm{Am},{ }^{152} \mathrm{Eu}, \mathrm{Y}$ and all the lanthanides listed in Table 1; afterwards, the organic phase loaded with the cations was contacted with a stripping solution containing the hydrophilic ligand. All the experiments were carried out according to the standard protocol described above. For the determination of the stripping kinetics, the organic phase was loaded with ${ }^{241} \mathrm{Am}$ and ${ }^{152} \mathrm{Eu}$ in the case of ligand $\mathbf{3}$, and with ${ }^{241} \mathrm{Am},{ }^{152} \mathrm{Eu}, \mathrm{Y}$ and all the lanthanides in the case of ligand $\mathbf{1}$ by extracting from $3 \mathrm{M} \mathrm{HNO}_{3}$. The loaded organic phases were separated and contacted with solutions of $0.005 \mathrm{M} 1$ in $1 \mathrm{M} \mathrm{HNO}_{3}$ and $0.01 \mathrm{M} 3$ in $0.1 \mathrm{M} \mathrm{HNO}_{3}$ for different mixing time. 
Table 1 Composition of the simulated HAR solution used in the extraction experiments.

\begin{tabular}{llll}
\hline Element & $\begin{array}{l}\text { Concentration } \\
(\mathbf{m g} / \mathbf{L})\end{array}$ & Element & $\begin{array}{l}\text { Concentration } \\
(\mathbf{m g} / \mathbf{L})\end{array}$ \\
\hline${ }^{241} \mathrm{Am}$ & Traces & $\mathrm{Pr}$ & 291 \\
${ }^{152} \mathrm{Eu}$ & Traces & $\mathrm{Nd}$ & 1020 \\
$\mathrm{Y}$ & 104 & $\mathrm{Sm}$ & 198 \\
$\mathrm{La}$ & 335 & $\mathrm{Eu}$ & 48 \\
$\mathrm{Ce}$ & 764 & $\mathrm{Gd}$ & 83 \\
\hline
\end{tabular}

\section{Synthesis}

The new complexing agent $\mathbf{1}$ was synthesized according to Scheme 1.<smiles>N#CC(CO)(CO)CO</smiles>

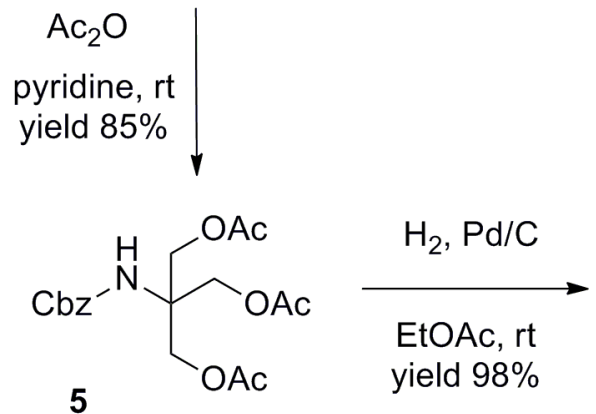

5<smiles>CC(=O)OCC(N)(COC(C)=O)COC(C)=O</smiles><smiles>Cc1ccc2ccc3ccc(C)nc3c2n1</smiles>
$70 \% \mathrm{HNO}_{3}, 100^{\circ} \mathrm{C}$ yield $75 \%$<smiles>O=C(O)c1ccc2ccc3ccc(C(=O)O)nc3c2n1</smiles>

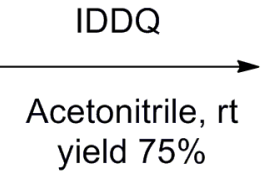<smiles>CC(=O)OCC(COC(C)=O)(COC(C)=O)NC(=O)c1ccc2ccc3ccc(C(=O)NC(COC(C)=O)(COC(C)=O)COC(C)C)nc3c2n1</smiles><smiles>CO[Mg]O[Mg]</smiles><smiles>O=C(NC(CO)(CO)CO)c1ccc2ccc3ccc(C(=O)NC(CO)(CO)CO)nc3c2n1</smiles>

Scheme 1 Synthesis of compound 1 via acetyl/Cbz orthogonal protection.

According to the synthetic procedure already known in literature [49,50], the commercially available precursor neocuproine (8) is oxidized to the corresponding dialdehyde (9) by using the mildly oxidizing agent $\mathrm{SeO}_{2}$ in refluxing 1,4-dioxane [49]. The compound 9 is then converted to the corresponding dicarboxylic acid (2) by oxidation with refluxing $70 \% \mathrm{HNO}_{3}$. The 1,10-phenanthroline-2,9dicarboxylic acid (2) was conjugated to trisacetylated TRIS (6) as shown in Scheme 1 (see ESM for details on the synthesis of compounds 5, 6, 7 and 1). For an efficient coupling between the amine and the dicarboxylic acid avoiding the formation of ester byproducts it was required to protect the alcoholic $\mathrm{OH}$ functions by introducing an easily removable group. We therefore protected the amine function with $\mathrm{Cbz}$, reacting the commercially available TRIS (10) with $\mathrm{Cbz}-\mathrm{Cl}$ in presence of $\mathrm{NaHCO}_{3}$ to give, after 
precipitation from diisopropylether, the desired product 4. Acetylation of hydroxy groups proceeded with high yield and smoothly to give intermediate 5, which was purified by flash chromatography before the $\mathrm{Cbz}$ deprotection step that allowed obtaining the pure product 6. All the products were characterized by proton NMR and ESI-MS. The coupling reaction between the phenanthroline-diacid (2) and acetylated TRIS (6) needed to be studied into details. Several coupling agents such as DCC, EDC or HBTU were tested but gave unsatisfactory results. Using 1-isobutoxycarbonyl-2-isobutoxy-1,2-dihydroquinoline (IDDQ) it was possible to isolate the product 7 with $75 \%$ yield after silica flash chromatography (Scheme 1). The final deacetylation step proceeded by using Zemplen method, a transesterification reaction with sodium methoxide in methanol. After quenching, the product could be obtained in $80 \%$ yields without further purifications, and was fully characterized by means of ${ }^{1} \mathrm{H},{ }^{13} \mathrm{C}$ NMR and ESI-MS techniques. The ligand $\mathbf{1}$, despite of the presence of six $\mathrm{OH}$ groups is insoluble in water at $\mathrm{pH}>0$ and is only moderately soluble in $\mathrm{HNO}_{3} 1 \mathrm{~mol} / \mathrm{L}$. Evidently the flat and rigid central phenanthroline units can aggregate by hydrophobic effects by stacking one onto the others, thus minimizing the unfavourable interactions of the aromatic nuclei with water molecules and exposing the hydrophilic groups to the exterior polar solvent.

\section{Complexing properties}

\section{Initial Screening Tests}

The aim of these preliminary screening tests was to establish the affinity of the hydrophilic ligands towards Am(III). The hydrophilic ligands have to selectively complex the Am(III) cation in order to prevent its extraction into the organic phase by TODGA, extractant well known to co-extract both An and Ln [51, 52]. The compound 1 was tested in the $\mathrm{c}_{\mathrm{HNO}}$ range 1 to $4 \mathrm{M}$ and interesting properties were observed (Table 2). For example with $\mathrm{c}_{\mathrm{HNO} 3}=1 \mathrm{M}$, the value of $\mathrm{D}_{\mathrm{Am}}$ decreases from 23.6 (indicated as blank experiment) to 0.82 when the ligand $\mathbf{1}$ is introduced in the aqueous phase. Under these conditions the compound $\mathbf{1}$ is therefore able to separate Am from $\mathrm{Eu}$ with a very high separation factor $\left(\mathrm{SF}_{\mathrm{Eu} / \mathrm{Am}}=42\right)$. When the TODGA concentration in the organic phase or the nitric acid concentration in the aqueous phase is higher, very high $\mathrm{D}_{\mathrm{M}}$ are obtained and no separation could be achieved. As expected, the global result is a competition between the strength of the aqueous ligand and the organic extractant.

Table 2 Results of the screening tests with ligand 1. Organic phase: 0.05M TODGA in kerosene/1-octanol 95:5 v/v; Aqueous phase: $0-0.025 \mathrm{M} \mathrm{1}, 0.5 \mathrm{M} \mathrm{NH}_{4} \mathrm{NO}_{3}$, spiked with ${ }^{241} \mathrm{Am}$ and ${ }^{152} \mathrm{Eu}$ in $1-3 \mathrm{M} \mathrm{HNO}$ init•

\begin{tabular}{ccccl}
\hline \multirow{2}{*}[1]{$\mathrm{M}$} & \multicolumn{4}{c}{$\left[\mathrm{HNO}_{3}\right]_{\text {init }} \mathrm{M}$} \\
\cline { 2 - 4 } & 1 & 2 & 3 & \\
\hline \multirow{2}{*}{ blank $^{\mathrm{a}}$} & $>100$ & $>100$ & $>100$ & $\mathrm{D}_{\mathrm{Eu}}$ \\
& 23.6 & $>100$ & $>100$ & $\mathrm{D}_{\mathrm{Am}}$ \\
\hline \multirow{2}{*}{0.01} & 34.3 & $>100$ & & $\mathrm{D}_{\mathrm{Eu}}$ \\
& 0.82 & 16.4 & - & $\mathrm{D}_{\mathrm{Am}}$ \\
\hline \multirow{2}{*}{0.025} & - & $>100$ & $>100$ & $\mathrm{D}_{\mathrm{Eu}}$ \\
& & 3.4 & 62.9 & $\mathrm{D}_{\mathrm{Am}}$ \\
\hline \multicolumn{2}{c}{${ }^{2}$ no ligand in the aqueous phase; n.c.: not computed }
\end{tabular}

An attempt to compare the extracting properties of $\mathbf{1}$ to those of $\mathbf{2}$ and $\mathbf{3}$ was performed. Unfortunately, because of the very limited solubility of 2 , this ligand could be tested only at $[2]=0.017 \mathrm{M}$ in $3.82 \mathrm{M} \mathrm{HNO}_{3}$, but the very high distribution ratios $\left(\mathrm{D}_{\mathrm{M}}>100\right)$ did not allow to evaluate its Eu/Am selectivity. The same solubility limits were observed for ligand $\mathbf{3}$ even if it is soluble at low $\left[\mathrm{HNO}_{3}\right]$. In this case, a noteworthy result was obtained with an extracting system composed of $0.02 \mathrm{M} 3$ solution in $0.1 \mathrm{M} \mathrm{HNO}_{3}+0.5 \mathrm{M}$ $\mathrm{NH}_{4} \mathrm{NO}_{3}$ aqueous phase and 0.2M TODGA in kerosene/octanol 95/5 v/v. In comparison with a blank experiment without any ligand in the aqueous phase $\mathrm{D}_{\mathrm{Am}}=32.4, \mathrm{D}_{\mathrm{Eu}}>100$ and $\mathrm{SF}_{\mathrm{Eu} / \mathrm{Am}}>3.09$ (see Table ESM1 in Electronic Supplementary Material), the introduction of 3 in the aqueous phase caused a $D_{A m}$ decrease by a factor of nearly $250\left(D_{A m}=0.14\right)$, while the $D_{E u}$ largely remained 
above the unit $\left(\mathrm{D}_{\mathrm{Eu}}=2.82\right)$, corresponding to a final separation factor $\mathrm{SF}_{\mathrm{Eu} / \mathrm{Am}}>20$. If the ligand concentration increases to $0.05 \mathrm{M}$, the $\mathrm{D}_{\mathrm{Eu}}$ value decreases below the unit and no separation could be achieved.

Considering the experimental conditions adopted in these screening tests, the combined use of TODGA and ligand 1 allows remarkable separation at $1 \mathrm{M} \mathrm{HNO}_{3}$, while with ligand $\mathbf{3}$ a fair separation could be obtained with lower acidic conditions.

\section{Selective Am(III) Stripping}

These encouraging preliminary experimental outcomes suggested that compounds $\mathbf{1}$ and $\mathbf{3}$ might be successfully exploited as selective stripping agents in $i$-SANEX (or similar) process. A new series of experiments was therefore performed, to check the properties of these phenanthroline derivatives in the selective stripping of Am(III) from a loaded TODGA-based organic phase coming from a preceding loading extraction step. TODGA is able to extract over 99.9\% of the Am and Eu present in the $3 \mathrm{M} \mathrm{HNO}_{3}$ aqueous feed. However, this neutral ligand is able to extract $\mathrm{HNO}_{3}$, as already published [53, 54]. In the tests conditions, the $\mathrm{c}_{\mathrm{HNO}}$ in the organic phase is around $0.22 \mathrm{M}$. In the following stripping test, this nitric acid could be partially transferred to the aqueous phase to differing extents according to the initial acidity of the stripping phase. Given the importance of the pH conditions in the stripping step, the initial aqueous $\mathrm{HNO}_{3}$ concentrations of the stripping solutions (without the stripping agents), as well as the equilibrium $\mathrm{HNO}_{3}$ concentrations (after the contact with the organic phase loaded from $3 \mathrm{M} \mathrm{HNO}$ solution), were determined by volumetric titration with $\mathrm{NaOH}$ standard solutions, and the results are shown in Figure ESM1 in the Electronic Supplementary Material. Interestingly, it can be observed that at low initial $\mathrm{HNO}_{3}$ concentrations, the $\left[\mathrm{HNO}_{3}\right]$ equilibrium value is strongly different from the initial one. Moreover, the stripping capability of nitric acid solutions (without the complexing agent) towards the loaded TODGA-based organic phase was checked, in order to better clarify the behavior of TODGA in the stripping step. These data are reported in all the following Tables 3-5 as blank experiments. Thus, several loaded organic phases were contacted with different stripping solutions containing the hydrophilic phenanthroline ligands and different $\mathrm{HNO}_{3}$ contents.

Table 3 Results of the stripping tests with ligand 1. Organic Phase: 0.05M TODGA solution in kerosene/1-octanol 95:5 v/v loaded with ${ }^{241} \mathrm{Am}$ and ${ }^{152} \mathrm{Eu}$ in a previous extraction step; Aqueous Phase: $0.0025-0.02 \mathrm{M} 1$ in $0.5-2 \mathrm{M} \mathrm{HNO}_{3 \text { init }}$.

\begin{tabular}{|c|c|c|c|c|c|c|c|}
\hline \multirow{2}{*}[\mathbf{1}]{$\mathrm{M}$} & \multicolumn{7}{|c|}{$\left[\mathrm{HNO}_{3}\right]_{\text {init }} \mathrm{M}$} \\
\hline & 0.5 & 1 & 1.3 & 1.4 & 1.5 & 2 & \\
\hline \multirow{2}{*}{ blank $^{\mathrm{a}}$} & 7.33 & 40.6 & 97.7 & $>100$ & $>100$ & $>100$ & $\mathrm{D}_{\mathrm{Eu}}$ \\
\hline & 1.08 & 5.42 & 12.3 & 16.0 & 23.1 & 69.6 & $\mathrm{D}_{\mathrm{Am}}$ \\
\hline \multirow{2}{*}{0.0025} & 1.66 & & & & & & $\mathrm{D}_{\mathrm{Eu}}$ \\
\hline & 0.08 & & & & & & $\mathrm{D}_{\mathrm{Am}}$ \\
\hline \multirow{2}{*}{0.005} & & 9.91 & 27.8 & 47.0 & & & $\mathrm{D}_{\mathrm{Eu}}$ \\
\hline & & 0.36 & 0.97 & 2.59 & & & $\mathrm{D}_{\mathrm{Am}}$ \\
\hline \multirow{2}{*}{0.01} & & & & & 44.3 & & $\mathrm{D}_{\mathrm{Eu}}$ \\
\hline & & & & & 1.45 & & $\mathrm{D}_{\mathrm{Am}}$ \\
\hline \multirow{2}{*}{0.02} & & & & & & $>100$ & $\mathrm{D}_{\mathrm{Eu}}$ \\
\hline & & & & & & 4.34 & $\mathrm{D}_{\mathrm{Am}}$ \\
\hline
\end{tabular}

Table 4 Results of the stripping tests with ligand 3. Organic Phase: 0.2M TODGA in kerosene/1-octanol 95:5 v/v loaded with ${ }^{241}$ Am and ${ }^{152} \mathrm{Eu}$ in a previous extraction step; Aqueous phase: $0.01 \mathrm{M} 3$ in water or $0.1-0.25 \mathrm{M} \mathrm{HNO}$ init.

\begin{tabular}{cccccc}
\hline \multirow{2}{*}[3]{$\mathrm{M}$} & & \multicolumn{3}{c}{$\left[\mathrm{HNO}_{3}\right]_{\text {init }} \mathrm{M}$} & \\
\cline { 3 - 5 } & water & 0.1 & 0.2 & 0.25 & \\
\hline \multirow{2}{*}{ blank $^{\mathrm{a}}$} & 24.8 & 64.0 & $>100$ & $>100$ & $\mathrm{D}_{\mathrm{Eu}}$ \\
& 3.50 & 9.18 & 15.2 & 22.8 & $\mathrm{D}_{\mathrm{Am}}$ \\
\hline \multirow{2}{*}{0.01} & 1.26 & 9.31 & $>100$ & $>100$ & $\mathrm{D}_{\mathrm{Eu}}$ \\
& 0.09 & 0.44 & 4.02 & 5.79 & $\mathrm{D}_{\mathrm{Am}}$ \\
\hline
\end{tabular}

a no ligand in the aqueous phase 
The hydrophilic 1,10-phenanthroline derivatives 1 (see Table 3) and $\mathbf{3}$ (see Table 4) showed promising results. The data referring to $\mathbf{1}$ (see Table 3) confirmed the preliminary results obtained in the screening tests. Namely, the results at $0.5-1 \mathrm{M} \mathrm{HNO}_{3}$ suggest that an aqueous solution of $\mathbf{1}$ could be an effective Am stripping solution because, in comparison with the blank, it causes $\mathrm{D}_{\mathrm{Am}}$ to decrease by a factor of about 15 and the Eu/Am separation factor to increase from 7 to about 30. Compound 2 was tested at a ligand concentration of $0.01 \mathrm{M}$ in 2 and $3 \mathrm{M} \mathrm{HNO}_{3}$ stripping phases but with unsatisfactory (both $\mathrm{D}_{\mathrm{M}} \gg 100$ ) results, probably due to the high acidic conditions. As already observed for the analogue lipophilic 1,10-phenanthroline diamide [47], also in aqueous phase the electronwithdrawing ability of $\mathrm{C}=\mathrm{O}$ carbonyl group in both $\mathbf{1}$ and $\mathbf{2}$, decreasing the basicity of the phenanthroline $\mathrm{N}$ atoms, allows to complex metal ions at high nitric acid concentrations. Ligand $\mathbf{2}$ seems slightly more efficient than $\mathbf{1}$, featuring the same tetradentate donor set. A stripping solution of $0.01 \mathrm{M} 3$ in $0.1 \mathrm{M}$ nitric acid enables to obtain $\mathrm{D}_{\mathrm{Am}}=0.44$ (compared to 9.18 of the blank) and $\mathrm{SF}_{\mathrm{Eu} / \mathrm{Am}}=21$ (with respect to the TODGA selectivity that is around 8 [54]). Increases of $\mathrm{HNO}_{3}$ concentrations up to $0.25 \mathrm{M}$ fundamentally do not prevent to maintain a fair selectivity (see Table 4), but $\mathrm{D}_{\mathrm{Am}}$ increases above 1 . Extractions carried out upon the addition of $0.5 \mathrm{M}$ ammonium nitrate to the stripping solution also gave $\mathrm{D}_{\mathrm{Am}}$ values above unit, suggesting that a common anion (nitrate) effect is operative in these cases. In order to achieve a better understanding of the extracting phenomena, the kinetic behaviour of the system based on stripping agent 3 was investigated. Therefore, several organic phases were loaded with ${ }^{241} \mathrm{Am}$ and ${ }^{152} \mathrm{Eu}$ and then contacted with nitric acid solutions (blank) and $0.01 \mathrm{M}$ solutions of 3 in $0.1 \mathrm{M} \mathrm{HNO}$ by varying the mixing time from 2 to 60 minutes. The kinetic stripping experiments (see Figure ESM2) at different mixing times showed that the stripping phenomenon is fast and the equilibrium $\mathrm{D}_{\mathrm{M}(\mathrm{III})}$ were reached within 5 minutes for both Am and Eu. Thus the addition of the complexing agent 3 did not affect the stripping kinetics.

In order to check the effectiveness of the stripping phases based on ligands $\mathbf{1}$ and $\mathbf{3}$ with a HAR simulating solution (see Table 1 for composition), new tests were repeated starting from organic phases loaded with ${ }^{241} \mathrm{Am},{ }^{152} \mathrm{Eu}, \mathrm{Y}$ and all the lanthanides considered. Concerning 1, as reported in Table 5, several conditions were explored but, although at $\left[\mathrm{HNO}_{3}\right]_{\text {init }} \leq 1 \mathrm{M}$ values of $\mathrm{D}_{\mathrm{Am}}<1$ were observed, it was not possible to identify conditions able to selectively separate Am from the lightest lanthanide ions. The best results found (third column, Table 5: $\left[\mathrm{HNO}_{3}\right]_{\text {init }}=1 \mathrm{M},[\mathbf{1}]=0.005 \mathrm{M}$ ) show co-extraction of La, Ce, Pr and Nd from a loaded 0.05M TODGA solution. At $1 \mathrm{M} \mathrm{HNO}_{3}$ and in absence of ligand in the aqueous phase, $\mathrm{D}_{\mathrm{La}-\mathrm{Nd}}<1$ are observed at [TODGA] $=0.05 \mathrm{M}$ but these values become higher than 1 by increasing TODGA concentration to $0.2 \mathrm{M}$ where, however, Am(III) was also extracted in the organic layer. Attempts to restore the Am(III) stripping in water were carried out by increasing ligand $\mathbf{1}$ concentration but were jeopardized by its low water solubility. It has to be noted that the stripping system composed of a $0.05 \mathrm{M}$ TODGA organic phase and the $0.005 \mathrm{M}$ of 1 in $1 \mathrm{M} \mathrm{HNO}_{3}$ stripping solution could still be a good candidate for the Am stripping from the heaviest lanthanides and could find application if a small contamination of the lightest lanthanides ( $\mathrm{La}, \mathrm{Ce}, \mathrm{Pr}$ and $\mathrm{Nd}$ ) in the An product could be accepted. Surely, the data clearly show that $\mathbf{1}$ has some affinity for $\mathrm{La}, \mathrm{Ce}, \mathrm{Pr}$ and $\mathrm{Nd}$, but the $\mathrm{D}_{\mathrm{M}}$ values for these lanthanides depend on $\left[\mathrm{HNO}_{3}\right]$ and $[$ TODGA $] /[1]$ ratio. Under the best conditions found $\left(\left[\mathrm{HNO}_{3}\right]_{\text {init }}=1 \mathrm{M},[\mathbf{1}]=0.005 \mathrm{M}\right)$, stripping kinetics was also evaluated and, as shown in Figure ESM3, the equilibrium could be attained after 5 minutes. Even in this case, hence, the addition of the complexing agent to the nitric acid stripping phase does not slow down the stripping kinetics in the time range considered.

Table 5 Results of the stripping tests with ligand 1. Organic Phase: TODGA solution loaded in a previous extraction step with HAR elements; Aqueous phase: $0-0.01 \mathrm{M} 1$ in $0.5-2 \mathrm{M} \mathrm{HNO}_{3 \text { init }}$.

\begin{tabular}{|c|c|c|c|c|c|c|c|c|c|}
\hline [TODGA] M & \multicolumn{3}{|c|}{0.05} & \multirow{2}{*}{\multicolumn{2}{|c|}{$\begin{array}{c}0.1 \\
1\end{array}$}} & \multicolumn{4}{|c|}{0.2} \\
\hline$\left[\mathrm{HNO}_{3}\right]_{\text {init }} \mathrm{M}$ & 0.5 & \multicolumn{2}{|c|}{1} & & & \multicolumn{2}{|c|}{1} & \multicolumn{2}{|c|}{2} \\
\hline [1] M & 0 & 0 & 0.005 & 0 & 0.005 & 0 & 0.005 & 0 & 0.01 \\
\hline $\mathrm{D}_{\mathrm{Y}}$ & 8.32 & 41.9 & 36.6 & - & - & $>100$ & - & $>100$ & $>100$ \\
\hline $\mathrm{D}_{\mathrm{La}}$ & $<0.001$ & 0.01 & $<0.001$ & - & - & 12.4 & - & 55.0 & 11.9 \\
\hline $\mathrm{D}_{\mathrm{Ce}}$ & 0.06 & 0.22 & 0.13 & - & - & 26.5 & - & $>100$ & 28.3 \\
\hline $\mathrm{D}_{\mathrm{Pr}}$ & 0.13 & 0.43 & 0.29 & - & - & 57.1 & - & $>100$ & 79.4 \\
\hline $\mathrm{D}_{\mathrm{Nd}}$ & 0.21 & 0.83 & 0.57 & - & - & $>100$ & - & $>100$ & $>100$ \\
\hline
\end{tabular}




\begin{tabular}{|c|c|c|c|c|c|c|c|c|c|}
\hline $\mathrm{D}_{\mathrm{Sm}}$ & 1.24 & 4.94 & 3.42 & - & - & $>100$ & - & $>100$ & $>100$ \\
\hline $\mathrm{D}_{\mathrm{Eu}}$ & 2.47 & 10.1 & 7.07 & - & - & $>100$ & - & $>100$ & $>100$ \\
\hline $\mathrm{D}_{\mathrm{Gd}}$ & 3.35 & 6.64 & 5.27 & - & - & $>100$ & - & $>100$ & $>100$ \\
\hline $\mathrm{D}_{\mathrm{Eu}(\gamma)}$ & 2.31 & 13.5 & 7.18 & $>100$ & 76.7 & $>100$ & $>100$ & $>100$ & $>100$ \\
\hline $\mathrm{D}_{\mathrm{Am}}$ & 0.50 & 1.76 & 0.42 & 12.6 & 3.10 & $>100$ & 13.7 & $>100$ & $>100$ \\
\hline
\end{tabular}

Several experimental conditions were also tested with ligand $\mathbf{3}$, such as the influence of ligand concentration, ammonium nitrate concentration and $\mathrm{pH}$ (see Table ESM2), but all the attempts were negative. In comparison with the results obtained with the spiked feed (see Table 4), the stripping performance of the $0.01 \mathrm{M} 3$ solution in $0.1 \mathrm{M} \mathrm{HNO}_{3}$ was lower: in particular, $\mathrm{D}_{\mathrm{Am}}$ rises from 0.44 to 2.22. At fixed $\mathrm{HNO}_{3}$ concentration, increasing the ligand concentration up to the solubility limit caused a $\mathrm{D}_{\text {Am }}$ decrease that however remains higher than 1 .
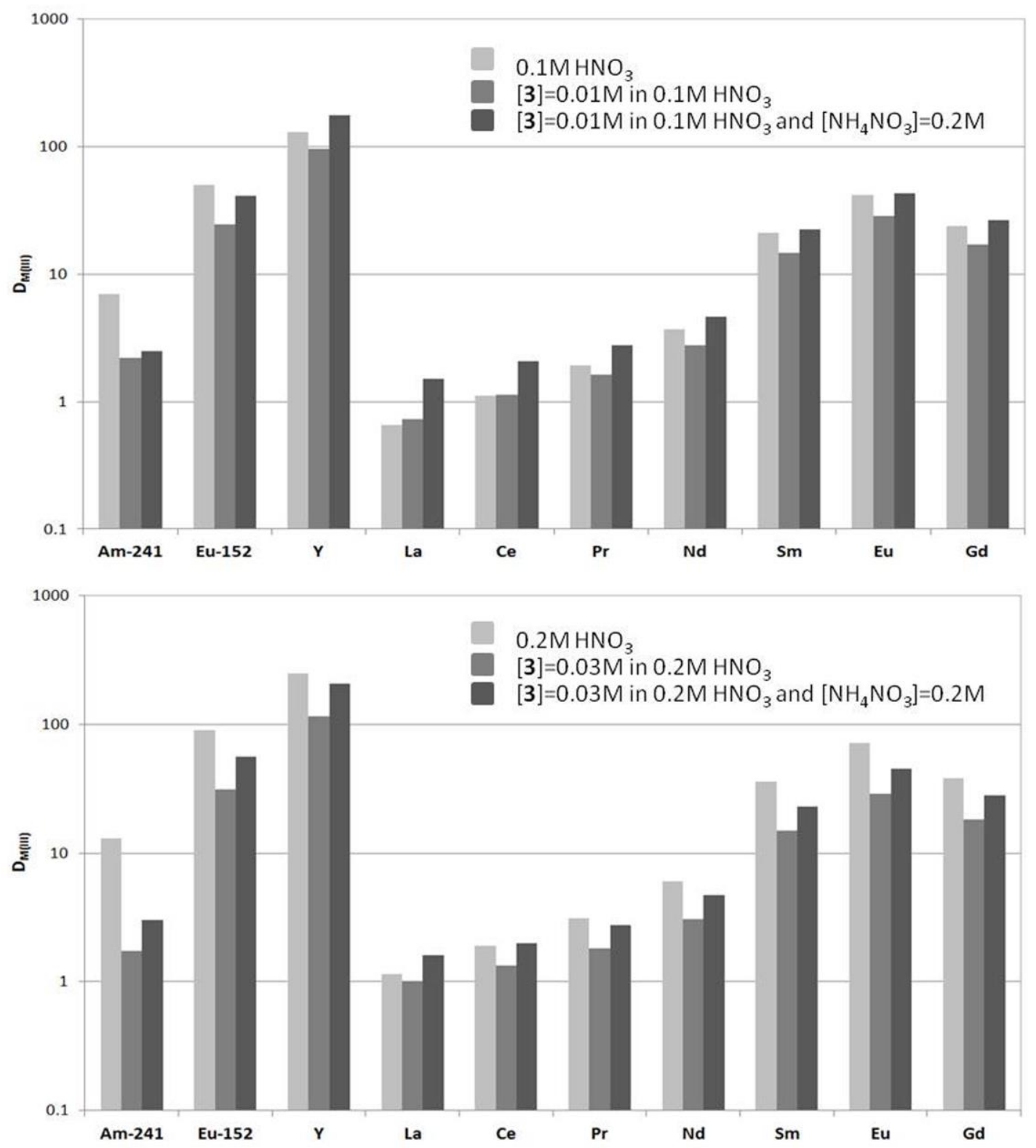

Figure 2 Distribution coefficients for the back-extraction of HAR elements into $0.1 \mathrm{M}$ (bottom) and $0.2 \mathrm{M} \mathrm{HNO}_{3}$ stripping solutions (top) without ligand $\mathbf{3}$ (light grey), with ligand $\mathbf{3}$ (grey) and with ligand $\mathbf{3}$ and ammonium nitrate (dark grey).

From the data reported in Figure 2 it can be seen that the distribution coefficient of the lightest lanthanides, and in particular of La, is close to 1 when $0.1 \mathrm{M} \mathrm{HNO}_{3}$ is used and increases just higher than 1 when $0.2 \mathrm{M} \mathrm{HNO}_{3}$ is used (see columns in light grey in Figure 2, top and bottom). However, in the same conditions $\mathrm{D}_{\mathrm{Am}}$ remains around 10. This behaviour seems linked to the fact that the lightest 
lanthanides, such as La and Ce, are the less extracted cations by TODGA and the ones more easily released in the aqueous phase, in particular at such low acidity. The effect of the addition of the phenanthroline ligand to the stripping phase (see grey columns in Figure 2, top and bottom) is mainly noticeable on the $\mathrm{D}_{\mathrm{Am}}$ decrease, that still remains above unity, and to a lesser extent on the $\mathrm{D}$ of the other elements, thus showing a lower affinity of $\mathbf{1}$ for lanthanides. Therefore, it has to be concluded that any stripping solution in $0.1 \mathrm{M} \mathrm{HNO}_{3}$, with or without a complexing agent, is able to strip La from a loaded TODGA-based organic phase. This could be avoided by the addition of ammonium nitrate to the $0.1 \mathrm{M} \mathrm{HNO}_{3}$ solution by exploiting the "common anion effect" and with a only slight effect on $\mathrm{D}_{\mathrm{Am}}$ (see dark grey columns in Figure 2 top) or by increasing the acidity of the stripping solution but with the drawback to also increase $\mathrm{D}_{\mathrm{Am}}$. Unfortunately, in the case of $\mathbf{3}$, no experimental conditions could be found where $\mathrm{D}_{\mathrm{Am}}$ are clearly $<1$. The modest solubility of this ligand limits its application: clear solutions of $\mathbf{3}$ could be obtained only at nitric acid concentrations below or, at the most, equal to $0.1 \mathrm{M}$, conditions where the release of the lightest lanthanides by TODGA could not be hampered. All these limiting factors thus prevent from finding, for this ligand, conditions suitable for an industrial Am separation process at least from HAR.

\section{CONCLUSIONS}

The new hydrophilic ligand $\mathbf{1}$ for the selective Am(III) stripping in the advanced reprocessing of SNF was synthesized and studied showing, for the first time, the potentiality of the hydrophilic diamide functionalised phenanthroline structure in nuclear applications. Comparisons with other two 1,10-phenanthroline-based ligands, 2 and 3, whose Am stripping properties have also been assessed, were made for the first time. The experimental work pointed out that $\mathbf{1}$ is surely the most promising compound among the three considered, even if its application is strongly limited by its low solubility in aqueous nitric acid solutions. The data collected confirmed that exploiting the preorganization of soft $\mathrm{N}$-donor atoms in the rigid system of 1,10-phenanthroline, in combination with hard amide $\mathrm{C}=\mathrm{O}$ groups, leads to a fast, efficient and quite selective separation of $\mathrm{Am}(\mathrm{III})$ from Eu(III) under certain conditions, in agreement with what observed for similar lipophilic 1,10-phenanthroline derivatives and recently reported in literature. In the best experimental conditions found, the combined use of the lipophilic TODGA in the organic phase and the hydrophilic 1 in the aqueous phase does feature a separation factor $\mathrm{SF}_{\mathrm{Eu} / \mathrm{Am}}$ of around 30 and a fast kinetics. The system efficacy is, however, severely reduced when passing from a spiked aqueous feed to a HAR-simulating feed due to solubility limitations of $\mathbf{1}$ in water. Therefore, the main drawback of this class of ligands lies in their limited solubility at the nitric acid concentrations of relevance for the $i$-SANEX process. Their rather straightforward and cheap synthesis, however, endows them of great potentialities of improvement: modifications of the phenanthroline appended groups, for instance, to introduce more polar/charged moieties, are currently under study with the specific aim of increasing ligand solubility and loading capacity in the conditions of interest for the treatment of SNF.

\section{Acknowledgements}

Financial support from the Nuclear Fission Safety Program of the European Union is gratefully acknowledged (Project ACSEPT, Contract No. FP7-CP-2007-211 267). We also thank the Centro Interdipartimentale di Misure “G. Casnati” at Università di Parma for the use of NMR facilities.

\section{References}

1. Salvatores M, Palmiotti G (2011) Radioactive waste partitioning and transmutation within advanced fuel cycles: Achievements and challenges. Progress in Particle and Nuclear Physics 66:144-166.

2. Magill J, Berthou V, Haas D, Galy J, Schenkel R, Wiese HW, Heusener G, Thommasi J, Youinou G (2003) Impact limits of partitioning and transmutation scenarios on the radiotoxicity of actinides in radioactive waste. Nucl Energy 42:263-277.

3. International Atomic Energy Agency, Technical Reports Series, no. 435, Vienna, Austria, 2004. 
4. Bourg S, Caravaca C, Ekberg C, Hill C, Rhodes C (2009) ACSEPT, Toward the future demonstration of advanced fuel treatments. Proceedings of GLOBAL 2009, Paris, France, Sept 6-11, 2009 (Paper 9185).

5. Madic C, Hudson MJ, Liljenzin JO, Glatz JP, Nannicini R, Facchini A, Kolarik Z, Odoj R (2000) New partitioning techniques for minor actinides. European Commission: Luxembourg, EUR 19149.

6. Madic C, Testard F, Hudson MJ, Liljenzin JO, Christiansen B, Ferrando M, Facchini A, Geist A, Modolo G, GonzalezEspartero A, De Mendoza J (2004). PARTNEW-New solvent extraction processes for minor actinides. Commissariat á l’Énergie Atomique: France, CEA-R-6066.

7. Madic C, Hudson MJ, Baron P, Ouvrier N, Hill C, Arnaud F, Espartero AG, Desreux JF, Modolo G, Malmbeck R, Bourg S, De Angelis G, Uhlir J (2006) EUROPART Integrated Project, FISA Conference, Luxembourg.

8. Madic C, Boullis B, Baron P, Testard F, Hudson MJ, Liljenzin JO, Christiansen B, Ferrando M, Facchini A, Geist A, Modolo G, Espartero AG, De Mendoza J (2007) Futuristic back-end of the nuclear fuel cycle with the partitioning of minor actinides. J Alloys Comp 444-445:23-27.

9. Bourg S, Hill C, Caravaca C, Rhodes C, Ekberg C, Taylor R, Geist A, Modolo G, Cassayre L, Malmbeck V, Harrison M, de Angelis G, Espartero A, Bouvet S, Ouvrier N. (2011) ACSEPT-Partitioning technologies and actinide science: towards pilot facilities in Europe. Nuclear Engineering and Design 241:3427- 3435.

10. Modolo G, Wilden A, Geist A, Magnusson D, Malmbeck R (2012) A review of the demonstration of innovative solvent extraction processes for the recovery of trivalent minor actinides from PUREX raffinate. Radiochim Acta 100:715-725.

11. Brown J, Carrott MJ, Fox OD, Maher CJ, Mason C, McLachlan F, Sarsfield MJ, Taylor RJ, Woodhead DA (2010) Screening of TODGA/TBP/OK solvent mixtures for the grouped extraction of actinides, IOP Conf. Series: Materials Science and Engineering 9, 2010, 012075 doi:10.1088/1757-899X/9/1/012075.

12. Miguirditchian M, Chareyre L, Hérès X, Hill C, Baron P, Masson M (2007) GANEX: Adaptation of the DIAMEX-SANEX Process for the group actinide separation. Proceedings of GLOBAL 2007, Boise, Idaho, USA.

13. Adnet JM, Miguirditchian M, Hill C, Hérès X, Lecomte M, Masson M, Brossard P, Baron P (2005) Development of new hydrometallurgical processes for actinide recovery: GANEX concept. Proceedings of GLOBAL 2005, Tsukuba, Japan, 2005 (Paper No.119).

14. Aneheim E, Ekberg C, Foreman MRS, Löfström-Engdahl E, Mabile N (2012) Studies of a solvent for GANEX applications containing CyMe 4-BTBP and DEHBA in cyclohexanone. Sep Sci Technol 47:663-669.

15. Brown J, McLachlan F, Sarsfield M, Taylor R, Modolo G, Wilden A (2012) Plutonium loading of prospective grouped actinide extraction (GANEX) solvent systems based on diglycolamide extractants. Solvent Extr Ion Exch 30:127-141.

16. Diamond RM, Street K, Seaborg GT (1954) An ion-exchange study of possible hybridized 5f bonding in the actinides. J Am Chem Soc 76:1461-1469.

17. Nash KL (1994) In Handbook on the Physics and Chemistry of Rare Earths. (Gschneider KAJr, Eyring L, Choppin GR, Lander GH, eds) North-Holland: Amsterdam, Vol 18, p 197. 
18. Alexander V (1995) Design and synthesis of macrocyclic ligands and their complexes of lanthanides and actinides. Chem Rev $95: 273-342$

19. Kolarik Z (2008) Complexation and separation of lanthanides(III) and actinides(III) by heterocyclic N-donors in solutions. Chem Rev 108:4208-4252.

20. Ekberg C, Fermvik A, Retegan T, Skarnemark G, Foreman MRS, Hudson MJ, Englund S, Nilsson M (2008) An overview and historical look back at the solvent extraction using nitrogen donor ligands to extract and separate An(III) from Ln(III). Radiochim Acta 96:225-233.

21. Hudson MJ, Harwood LM, Valentine D, Lewis FW (2013) Use of soft heterocyclic n-donor ligands to separate actinides and lanthanides. Inorg Chem 52:3414-3428.

22. Geist A, Mullich A, Magnusson D, Kaden P, Modolo G, Wilden A, Zevaco T (2012) Actinide(III)/Lanthanides(III) separation via selective aqueous complexation of actinides(III) using a hydrophilic 2,6bis(1,2,4-triazin-3-yl)-pirydine in nitric acid. Solv Extr Ion Exch 30:433-444.

23. Foreman M, Hudson MJ, Drew M, Hill C Madic C (2006) Complexes formed between the quadridentate, heterocyclic molecules 6,6-bis-(5,6-dialkyl-1,2,4-triazin-3-yl)-2,2-bipyridine (BTBP) and lanthanides(III): implications for the partitioning of actinides(III) and lanthanides(III). Dalton Trans 13:1645-1653.

24. Geist A, Hill C, Modolo G, Foreman MRS; Weigl M, Gompper K, Hudson MJ (2006) 6,6'-Bis(5,5,8,8-tetramethyl-5,6,7,8tetrahydro-benzo[1,2,4]triazin-3-yl)[2,2']bipyridine, an effective extracting agent for the separation of americium(III) and curium(III) from the lanthanides. Solvent Extr Ion Exch 24:463-483.

25. Magnusson D, Christiansen B, Foreman MRS, Geist A, Glatz JP, Malmbeck R, Modolo G, Serrano-Purroy D, Sorel C (2009) Demonstration of a SANEX process in centrifugal contactors using the CyMe4-BTBP molecule on a genuine fuel solution. Solvent Extr Ion Exch 27:97-106.

26. Lewis FW, Harwood LM, Hudson MJ, Drew MGB, Desreux JF, Vidick G, Bouslimani N, Modolo G, Wilden A, Sypula M, Vu TH Simonin JP (2011) Highly efficient separation of actinides from lanthanides by a phenanthroline-derived bis-triazine ligand. J Am Chem Soc 133:13093-13102.

27. Bencini A, Lippolis V (2010) 1,10-Phenanthroline: versatile building blocks for the construction of ligands for various purposes. Coord Chem Rev 254:2096-2180.

28. Sammes PG, Yahioglu G (1994) 1,10-Phenanthroline: a versatile ligand. Chem Soc Rev 23:327-334.

29. Luman CR, Castellano FN (2004) Comprehensive coordination chemistry II, Vol. 1; McCleverty, J. A.; Meyer, T. J., Eds., Elsevier: Oxford, 2004, pp 25-39.

30. Accorsi G, Listorti A, Yoosaf K, Armaroli N (2009) 1,10 Phenanthroline: versatile building blocks for luminescence molecules, materials and metal complexes. Chem Soc Rev 38:1690-1700. 
31. Xiao CL, Wang CZ, Yuan LY, Li B, He H, Wang S, Zhao YL, Chai ZF, Shi WQ (2014) Excellent Selectivity for Actinides with a Tetradentate 2,9-Diamide-1,10-Phenanthroline Ligand in Highly Acidic Solution: A Hard-Soft Donor Combined Strategy. Inorg Chem 53:1712-1720.

32. Bisson J, Dehaudt J, Charbonnel MC, Guillaneux D, Miguirditchian M, Marie C, Boubals N, Dutech G, Pipelier M, Blot V, Dubreuil D (2014) 1,10-phenantroline and non-symmetrical 1,3,5-triazine dipicolinamide-based ligands for group Actinide extraction. Chem A Eur J 20:7819-7829.

33. Bisson J, Berthon C, Berthon L, Boubals N, Dubreuil D, Charbonnel MC (2012) Effect of the structure of Amido-polynitrogen Molecules on the complexation of Actinides. Procedia Chemistry 7:13-19.

34. Dean NE, Hancock RD, Cahill CL, Frisch M (2008) Affinity of the highly preorganized ligand PDA (1,10-phenanthroline-2,9dicarboxylic acid) for large metal ions of higher charge. A crystallographic and thermodynamic study of PDA complexes of Thorium(IV) and the Uranyl(VI) ion. Inorg Chem 47:2000-2010.

35. Melton DL, VanDerveer DG, Hancock RD (2006) Complexes of Greatly Enhanced Thermodynamic Stability and Metal Ion Size-Based Selectivity, Formed by the Highly Preorganized Non-Macrocyclic Ligand 1,10-Phenanthroline-2,9-dicarboxylic Acid. A Thermodynamic and Crystallographic Study. Inorg Chem 45:9306-9314.

36. Gephart RT, Williams NJ, Reibenspies JH, De Sousa AS, Hancock RD (2008) Metal ion complexing properties of the highly preorganized ligand 2,9-bis(hydroxymethyl)-1,10-phenanthroline: A crystallographic and thermodynamic study. Inorg Chem 47:10342-10348.

37. Gephart RT, Williams NJ, Reibenspies JH, De Sousa AS, Hancock RD (2009) Complexation of metal ions of higher charge by the highly preorganized tetradentate ligand 2,9-bis(hydroxymethyl)-1,10-phenanthroline. A crystallographic and thermodynamic study. Inorg Chem 48:8201-8209.

38. Williams NJ, Balance DG, Reibenspies JH, Hancock RD (2010) Complexes of the highly preorganized ligand PDALC (2,9bis(hydroxymethyl)-1,10-phenanthroline) with trivalent lanthanides. A thermodynamic and crystallographic study. Inorg Chim Acta 363:3694-3699.

39. Merrill D, Hancock RD (2011) Metal ion selectivities of the highly preorganized tetradentate ligand 1,10-phenanthroline-2,9dicarboxamide with lanthanide(III) ions and some actinide ions. Radiochim Acta 99:161-166.

40. Zong R, Thummel RP (2004) 2,9-Di-(2'-pyridyl)-1,10-phenanthroline: A tetradentate ligand for Ru(II). J Am Chem Soc 126:10800-10801.

41. Cockrell GM, Zhang G, VanDerveer DG, Thummel RP, Hancock RD (2008) Enhanced metal ion selectivity of 2,9-Di-(pyridyl)-1,10-phenanthroline and its use as a fluorescent sensor for Cadmium (II). J Am Chem Soc 130:1420-1430.

42. Karmazin L, Mazzanti M, Gateau C, Hill C, Pécaut J (2002) The important effect of ligand architecture on the selectivity of metal ion recognition in $\mathrm{An}(\mathrm{III}) / \mathrm{Ln}(\mathrm{III})$ separation with N-donor extractants. Chem Commun 23:2892-2893.

43. Boone L, Mroz AE, VanDerveer DG, Hancock RD (2011) Metal ion coordinating properties of the highly preorganized tetradentate ligand 1,10-phenanthroline-2,9-dicarboxaldehyde-2,9-dioxime. Eur J Inorg Chem 17:2706-2711. 
44. Galletta M, Baldini L, Sansone F, Ugozzoli F, Ungaro R, Casnati A, Mariani M (2010) Calix[6]arene-picolinamide extractants for radioactive waste: effect of modification of the basicity of the pyridine $\mathrm{N}$ atom on the extraction efficiency and An/Ln separation. Dalton Trans. 39:2546-2553.

45. Macerata E, Castiglione F, Panzeri W, Mariani M, Sansone F, Casnati A, Mele A (2010) Assessing the mechanism of the synergistic action of calixarenes and Co-dicarbollides in lanthanide extractions. New J Chem 34:2552-2557.

46. Macerata E, Sansone F, Baldini L, Ugozzoli F, Brisach F, Haddaoui J, Hubscher-Bruder V, Arnaud-Neu F, Mariani M, Ungaro R, Casnati A (2010) Calix[6]arene-picolinamide extractants for radioactive waste treatment: effect of additional carboxy binding sites in the pyridine 6-positions on complexation, extraction efficiency and An/Ln separation. Eur J Org Chem 14:2675-2686.

47. Galletta M, Scaravaggi S, Macerata E, Famulari N, Mele A, Panzeri W, Sansone F, Casnati A, Mariani M (2013) 2,9Dicarbonyl-1,10-phenanthroline derivatives with unprecedented Am(III)/Eu(III) selectivity under highly acidic conditions. Dalton Trans 42:16930-16938.

48. Baldoli C, Rigamonti C, Maiorana S, Licandro E, Falciola L, Mussini PR. (2006) A new triferrocenyl tris(hydroxymethyl)aminomethane derivative as a highly sensitive electrochemical marker of biomolecules: application to the labelling of PNA monomers and their electrochemical characterization. Chem A Eur J 12:4091-4100.

49. Chandler CJ, Deady LW, Reiss JA (1981) Synthesis of some 2,9-disubstituted-1,10-phenanthroline. J Heterocyclic Chem 18:599.

50. De Cian A, DeLemos E, Mergny JL, Teulade-Fichou MP, Monchaud D (2007) Highly efficient G quadruplex recognition by bisquinolinium compounds. J Am Chem Soc 129:1856-1857.

51. Magnusson D, Christiansen B, Glatz, JP, Malmbeck R, Modolo G, Serrano-Purroy D, Sorel C (2009) Demonstration of a TODGA based extraction process for the partitioning of minor actinides from a PUREX raffinate. Solvent Extr Ion Exch 27:26-35.

52. Gujar RB, Ansari SA, Murali MS, Mohapatra PK, Manchanda VK (2010) Comparative evaluation of two substituted diglycolamide extractants for 'actinide partitioning'. J Radioanal Nucl Chem 284:377-385.

53. Geist A (2010) Extraction of nitric acid into alcohol: kerosene mixtures. Solvent Extr Ion Exch 28:596-607.

54. Geist A, Modolo G (2009) TODGA process development: an improved solvent formulation. Proceedings of GLOBAL 2009, Paris (France), Paper 9193, pp 1022-1026. 